\title{
Planning of resource maintenance at building of railway bridge
}

\author{
Michael Klykov ${ }^{1, *}$, Nikolay Grigoryev ${ }^{1}$, and Alexander Zemskov ${ }^{1}$ \\ ${ }^{1}$ Far Eastern State Transport University, Seryshev St.,47,Khabarovsk, 680021, Russia
}

\begin{abstract}
The Publication contains the results of research on the problem of resources provision perfecting of erection processes of railway bridges including consideration of forecasting demand questions to material resources, formations of delivery schedules of materials and designs, definitions of insurance reserves in regards to suppliers of material and technical production.
\end{abstract}

\section{Introduction}

The main purpose, which is pursued at planning of resources' provision of construction of railway bridges, is in such synchronisation of building schedules with the delivery schedules of stored resources which would supply enough high stability of timetables with minimisation of combined costs of bridge erection enterprise on the content of reserves, deliveries, losses owing to deficiency in materials and designs. Big reserve of stored resources supplies a higher stability of building processes with simultaneous increase of expenses of construction company on the content of reserves.

Reduction of temporary reserving of receipt of stored resources lowers the expenditures of construction company on their content. However, considerably expenses on deliveries and, particularly are increased, owing to deficiency in materials and designs. Hence, the problem of plan formation of material security for construction of railway bridges can be reduced to the task of search of optimum reserving of receipts of resources in view of stability of timetable, periodicity of receipts, reliability of suppliers. At the same time, target function looks like:

$$
\mathrm{W}=\mathrm{W}_{1}+\mathrm{W}_{2}+\mathrm{W}_{3} \rightarrow \mathrm{min},
$$

where: $\mathrm{W}_{1}$ is expenses, the appropriate strategies of forecasting of demand of construction company in material resources; $\mathrm{W}_{2}$ is expenditures on the content of current reserve and deliveries of resources; $\mathrm{W}_{3}$ is expenses on time reservation accounting reliability of suppliers.

\footnotetext{
*Corresponding author: msklykov@gmail.com
} 
Direct search of optimum sizes of time reservation of receipts material resources is difficult for the reason that the common size of reservation (reserve) acting as argument, is not controlled variable, as depends on residues of the reserve to the start and the end of the planning periods, volumes and the terms of deliveries of resources, volumes and the terms of consumption.

Creation unified model of plan formation of financial security of railway bridges construction practically is hard to carry out also because of plenty of various variables and limitations peculiar to given task. Therefore, taking into account rather weak feedback between forecasting of demand in resources, development of the plans of its realization in view of reliability of suppliers, is offered gradual optimisation of considered tasks, i.e. is supposed that

$$
\min \left(\mathrm{W}_{1}+\mathrm{W}_{2}+\mathrm{W}_{3}\right)=\min \mathrm{W}_{1}+\min \mathrm{W}_{2}+\min \mathrm{W}_{3} .
$$

During the first phase is defined demand of bridge erection enterprise in material resources. Then is developed conditionally optimal plan of realisation of expected calendar need for resources. On the third phase is corrected received delivery schedule in view of suppliers reliability.

\section{Planning of demand for material resources}

At definition of demand to materials, designs and articles as mathematical model of construction of bridges are used usually determined activity networks, and regulatory framework is developed on the basis of industrial norms pegged to local conditions, and the cards of standard need for designs and articles. However, revealing of demand in resources on the basis of detailed determined works timetable not always supplies a sufficient approach of planned rate of consumption to actual charge of materials, designs and articles that rather often results in formation of above permitted standard reserves of material resources or to occurrence of their deficiency.

Therefore, at planning of demand it is offered to take into account a stochastic nature of processes of erection of railway bridges. But for it predefined should be quantitative evaluation of stability of planned schedules on erection of railway bridges transitions from the standpoint of observance period of execution of works. For receipt of quantitative evaluations of stability of developing planned schedules of construction, in the divisions of public corporation of "Dalmostostroy", Open Company "MSK-10", Open Company "Building company Most-Vostok" data of scheduled and actual terms of performance of civil and erection works were accumulated and processed by methods of statistical analysis.

Analysis of empirical series forms of distribution of actual terms performances of works from the appropriate terms in planned schedules allowed to draw conclusion that this distribution is subject to normal law

$$
f(x)=\frac{t}{\sigma \sqrt{2 n}} 1 \frac{-\frac{(x-\bar{x})^{2}}{2 \sigma}}{},
$$

where: $\overline{\mathrm{x}}$ is mean of distribution of the values $\mathrm{x} ; \sigma$ is mean-square deviation.

For statistical check of put forward hypothesis of normal distribution of actual terms of timetables work delivery of planned schedules the criterion of B. Yastremsky was used who allows to give a direct answer to question of the measure of the discrepancy between empirical and theoretical distribution. Received results show that there are significant deviations of valid terms of performance of works on construction of bridges from terms in 
planned schedules.

The mean of distribution value $\overline{\mathrm{X}}$ and mean-square deviation $(\sigma)$ of selected normal distribution of work schedule deviations in the organisations of public corporation of "Dalmostostroy", Open Company "MSK-10", Open Company "Building company MostVostok" was compiled in days: $\overline{\mathrm{x}}=-1,17, \sigma=17,34$. At the same time, in these building divisions high probability $\left[\mathrm{P}_{(\mathrm{x}>0)}\right]$ of conducting operations earlier of planned terms is installed. Dimension $\mathrm{a}=\left[\mathrm{P}_{(\mathrm{x}>0)}\right]$ equaled for about $48 \%$.

Along with the assessment of resistance of planned schedules from the standpoint of observance time period for doing the work of timetables of construction of railway bridges from the standpoint of preservation of scheduled duration of processes was performed. For this purpose in under study enterprises statistical information about deviations of actual durations of works from durations in planned schedules was assembled. Taking into account that in developing timetables duration of works vary in very wide range, comparison of deviations in absolute terms cannot be comparable. Therefore, all deviations of durations of works were presented to commensurable type by the way of sizes calculation $\beta$ :

$$
\beta=\frac{\mathrm{t}_{\mathrm{ij}}^{(\mathrm{e})}}{\mathrm{t}_{\mathrm{ij}}^{(\mathrm{o})}},
$$

where: $\mathrm{t}_{\mathrm{ij}}{ }^{\mathrm{e})}$ is effective running time $\mathrm{ij} ; \mathrm{t}_{\mathrm{ij}}{ }^{(\mathrm{o})}$ is baseline duration of work $\mathrm{ij}$. Selection of the values $\beta$ equaled 1348 data. Statistical analysis of empirical schedule of relative durations of works $\beta$ (Figure 1) revealed its relatively big asymmetric property what did not allow to accept hypothesis of normal distribution.

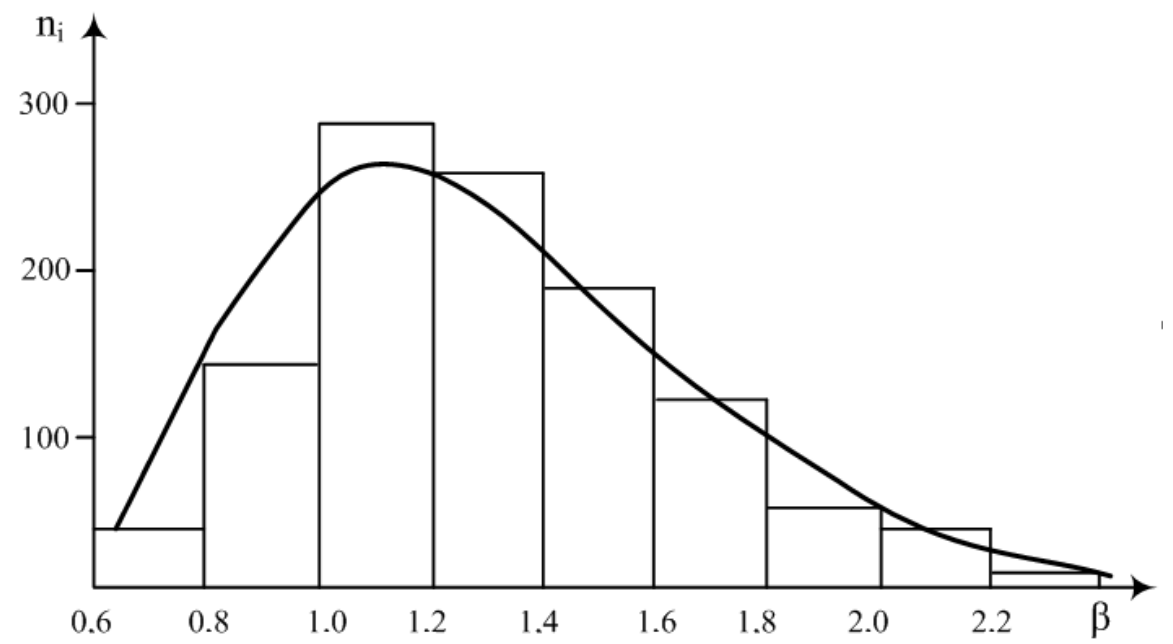

Fig.1. Histogram and distribution curve by 1348 deviations of actual durationsof works from calculated durations.

Therefore new hypothesis of subjection of distribution of the values $\beta$ to logarithmic normal law was put forward

$$
\varphi(\beta)=\frac{1}{\sigma \beta \sqrt{2 \pi}} \cdot 1-\frac{(\ln \beta-\mathrm{a})}{2 \sigma^{2}}
$$


Where: a and $\sigma$ there are parameters of normal distribution.

For the evidence of conformity of actual distribution of the values $\beta$ to chosen form of theoretical distribution theoretical frequencies were calculated and was made comparison with empirical schedule According to the criteria of Romanovsky and Yastremsky, protruding hypothesis found its acknowledgement. Performed analysis of planned schedules realisation of railway bridges construction showed necessity of the account of reliability of timetable at planning of material support. It means that at forecasting of demand to material production it is necessary to provide temporary reserving. The values of temporary reserving of demand as applied to all works of timetable should be such so that the minimum of losses of the enterprise be supplied which builds bridges, owing to deficiency in resources and expenditures to reserving of the need for materials and designs.

We in the beginning will consider definition of rational temporary reserving of demand to stored resources with reference to one work of building schedule. We will enter following designations: $\mathrm{P}(\mathrm{x})$ is probability of overtaking of elementary delivery $\mathrm{q}$ with reference to scheduled terms of the start and finish of work $T_{i}^{\left({ }^{\circ}\right)}, T_{j}^{\left({ }^{\circ}\right)}$ in the amount $x$ time units; $g$ is size of expenses for reserving of material resources per unit time; $g(\tau-x) P(x)$ is expenses connected with excessive temporary reserving $(\tau-\mathrm{x})$ of resources on timetable. Made up of these expenses enter payment for reserves, expenditures connected purely with storage of resources, losses from physical damage; $p$ ' is size of expenditures connected with the deficiency of stored time unit resources; $\mathrm{p}^{\prime}(\mathrm{x}-\tau) \mathrm{P}(\mathrm{x})$ is expenditures caused the deficiency of material resources and proportional durations of the deficiency, equal $(x-\tau)$. The main part of these expenditures is accounted for by the expense connected with increase of building period of bridges; $p$ " is size of expenditures owing to delayed supplying by storage resources not dependent from duration of the deficiency; $\quad \mathrm{p}$ " $(\mathrm{x}-$ $\tau) \mathrm{P}(\mathrm{x})$ is expenditures because of delay of delivery of materials on $(\mathrm{x}-\tau)$ time units and not dependent from duration of the deficiency (to those expenditures relate expenses connected with transition of teams, moves of machines and mechanisms); $w(\tau)$ is total average costs, the appropriate to temporary reserving of influx of resources, needed for performance of given work in the amount, equal $\tau$.

Mean of distribution of expenditures $\mathrm{w}(\tau)$ is defined

$$
\mathrm{w}(\tau)=\mathrm{g} \sum_{\mathrm{x}=0}^{\tau} \mathrm{P}(\mathrm{x})(\tau-\mathrm{x})+\mathrm{p}^{\prime}, \sum_{\mathrm{x}=\tau+1}^{\infty} \mathrm{P}(\mathrm{x})(\mathrm{x}-\tau)+\mathrm{p}^{\prime}, \quad \sum_{\mathrm{x}=\tau+1}^{\infty} \mathrm{P}(\mathrm{x}) .
$$

The decision of formulated task is reduced to finding of the value minimising function of expenditures $\mathrm{w}(\tau)$ under conditions of: $\tau$, $\mathrm{x}$ is whole non-negative numbers, $\mathrm{g}>0, \mathrm{p}^{\prime}>0$, $p ">0$ (Figure 2). To define the condition of the minimum for specified function of expenditures in overall view it is not represented possible, therefore process of optimisation we will break down for two phases. We during the first phase will define the condition of search $\tau^{*}$, which is that of the minimum of function $\mathrm{w}\left(\tau^{*}\right)$, including the first two summands, i.e.:

$$
\mathrm{w}\left(\tau^{*}\right)=\mathrm{g} \sum_{\mathrm{x}=0}^{\tau} \mathrm{P}(\mathrm{x})(\tau-\mathrm{x})+\mathrm{p}^{\prime} \sum_{\mathrm{x}=\tau+1}^{\infty} \mathrm{P}(\mathrm{x})(\mathrm{x}-\tau)
$$

On the second step of optimisation we will take into consideration that circumstance that the account of additional expenses not dependent from duration of the deficiency, will only increase a value $\tau^{*}$. Therefore we will implement a further verification of size $\tau$ by the way of direct calculation of the values of all function $\mathrm{w}(\tau)$, beginning with $\mathrm{w}\left(\tau^{*}\right)$ until the condition of the minimum $\mathrm{w}(\tau)$ will be performed. 


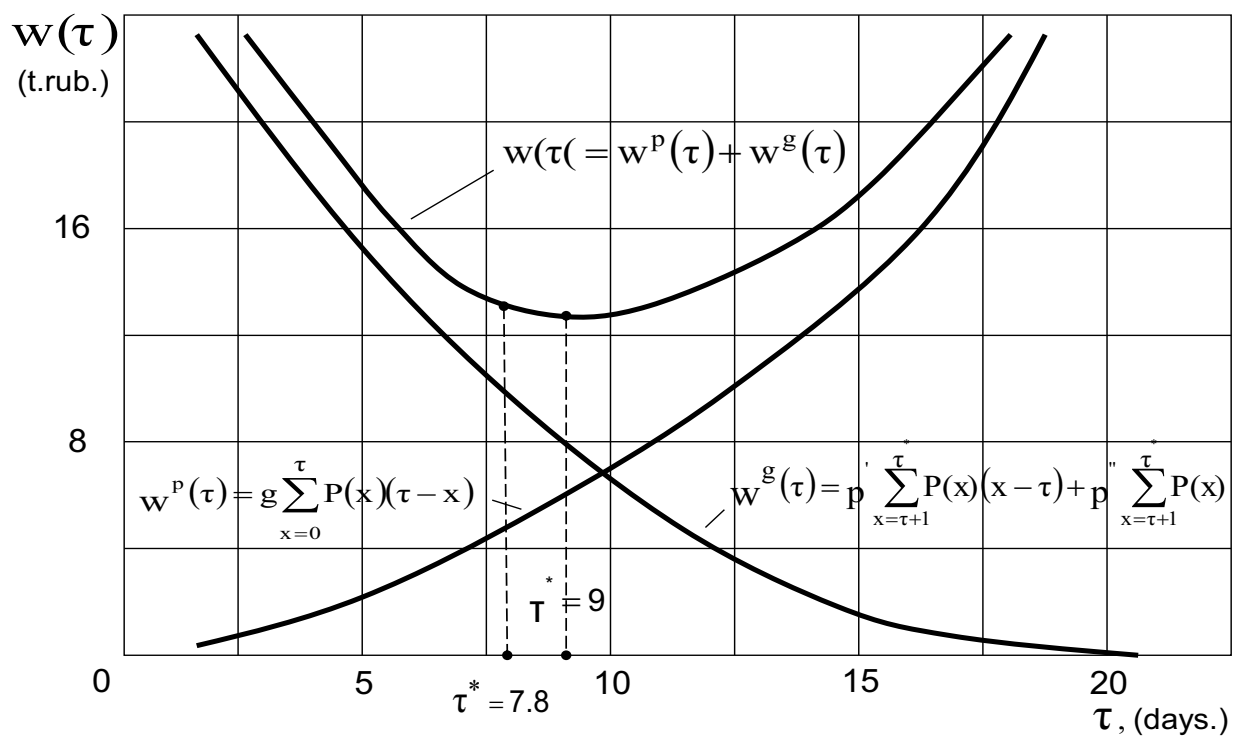

Fig.2. Dependence of expenses from size of temporary reserving $\tau$.

At search $\tau^{*}$ we use that circumstance that if value $\tau^{*}$ to increase or to diminish per unit time, then the appropriate average total expenditures will only increase, i.e. $\mathrm{w}\left(\tau^{*}-\right.$ 1) $>\mathrm{w}\left(\tau^{*}\right)<\mathrm{w}\left(\tau^{*}+1\right)$. For establishing of the rule, appropriate $\tau^{*}$,we will replace in function $\mathrm{w}(\tau)$, containing two first components, $\tau$ on $\tau+1$. After some transformations we will receive

$$
\mathrm{w}(\tau+1)=\mathrm{g} \sum_{\mathrm{x}=0}^{\tau} \mathrm{P}(\mathrm{x})(\tau-\mathrm{x})+\mathrm{g} \sum_{\mathrm{x}=0}^{\tau} \mathrm{P}(\mathrm{x})+\mathrm{p}^{\prime} \sum_{\mathrm{x}=\tau+1}^{+\infty} \mathrm{P}(\mathrm{x})(\mathrm{x}-\tau)+\mathrm{p}, \sum_{\mathrm{x}=\tau+1}^{+\infty} \mathrm{P}(\mathrm{x})
$$

Taking into account $\sum_{\mathrm{x}=\tau+1}^{\infty} \mathrm{P}(\mathrm{x})=\mathrm{a}-\sum_{\mathrm{x}=0}^{\tau} \mathrm{P}(\mathrm{x})$, we will record this equality as

$$
\mathrm{w}(\tau+1)=\mathrm{w}(\tau)+\left(\mathrm{p}^{\prime}+\mathrm{g}\right) \sum_{\mathrm{x}=0}^{\tau} \mathrm{P}(\mathrm{x})-\mathrm{ap}
$$

Replacing in received equality $\tau$ by $\tau-1$ we will receive

$$
\mathrm{w}(\tau-1)=\mathrm{w}(\tau)-\left(\mathrm{p}^{\prime}+\mathrm{g}\right) \sum_{\mathrm{x}=0}^{\tau-1} \mathrm{P}(\mathrm{x})+\mathrm{ap} \mathrm{p}^{\prime}
$$

Using two last expressions, we will rewrite the condition of the optimality of temporary reserving of the need for resources to one work as follows:

$$
\begin{gathered}
\mathrm{w}\left(\tau^{*}+1\right)-\mathrm{w}\left(\tau^{*}\right)=\left(\mathrm{p}^{\prime}+\mathrm{g}\right) \sum_{\mathrm{x}=0}^{\tau^{*}} \mathrm{P}(\mathrm{x})-\mathrm{ap}>0 \\
\mathrm{w}\left(\tau^{*}\right)-\mathrm{w}\left(\tau^{*}\right)=-\left(\mathrm{p}^{\prime}+\mathrm{g}\right) \sum_{\mathrm{x}=0}^{\tau^{*}-1} \mathrm{P}(\mathrm{x})+\mathrm{ap}>0 .
\end{gathered}
$$


For calculations we will present received ratios as follows:

$$
\sum_{\mathrm{x}=0}^{\tau^{*}-1} \mathrm{P}(\mathrm{x})<\frac{\mathrm{p}^{\prime}}{\mathrm{p}^{\prime}+\mathrm{g}}<\sum_{\mathrm{x}=0}^{\tau^{*}} \mathrm{P}(\mathrm{x}) .
$$

Computation algorithm $\tau^{*}$ consists in sequential calculation of left-hand and right parts of the last inequality until will not be found value $\tau^{*}$, at which it is executed. Procedures on definition $\tau^{*}$ are executed for all works of building timetable. Found optimum values of temporary advancing of the need for resources for all works timetables provide the basis for transition from time limits $\mathrm{T}_{\mathrm{i}}^{(\mathrm{o})}, \mathrm{T}_{\mathrm{j}}^{(\mathrm{o})}$ to the dates $\mathrm{T}^{(\tau)}{ }_{\mathrm{i}}, \mathrm{T}^{(\tau)}{ }_{\mathrm{j}}$ on the basis of ratios:

$$
\mathrm{T}_{\mathrm{i}}^{(\tau)}=\mathrm{T}_{\mathrm{i}}^{(\mathrm{o})}-\tau_{\mathrm{ij}} ; \mathrm{T}_{\mathrm{j}}^{(\tau)}=\mathrm{T}_{\mathrm{i}}^{(\tau)}+\mathrm{t}_{\mathrm{ij}}^{(\tau)}
$$

where: $\mathrm{T}_{\mathrm{i}}^{(\tau)}, \mathrm{T}_{\mathrm{j}}^{(\tau)}$ is initial and deadline of accomplishment of the work for forecasting of demand considering probability parameters of timetable; $t_{i j}{ }^{(\tau)}$ is durations of works determined in view of deviations of valid durations of works $t_{i j}{ }^{(e)}$ from durations $t_{i j}{ }^{(o)}$ in developing timetables.

Stochastic deviations nature of durations processes of bridges construction is taken into account by introduction to calculation of the values $\mathrm{t}_{\mathrm{ij}}{ }^{(\tau)}$ with probability belief $\mathrm{P}=0,954$. Pursuant to that, minimum possible duration of building process is defined:

$$
\mathrm{t}_{\mathrm{ij}}^{(\tau)}=\mathrm{t}_{\mathrm{ij}}^{(\mathrm{o})}(\operatorname{antiln}-2 \sigma) .
$$

Knowing values $T_{i}^{(\tau)}, T_{j}^{(\tau)}$ on all works of building timetable, can be calculated functions of demand $\mu_{\mathrm{zt}}^{(\tau)}$ for each day $\mathrm{t}$ of planning period $\left[\mathrm{T}_{\mathrm{o}}, \mathrm{T}_{\mathrm{p}]}\right]$.

\section{Planning of deliveries of material resources}

Scheduling problem of receipts of materials, designs and articles to under construction objects is central in the problem of synchronisation of suppliers activity and enterprises on construction of bridges. Absence of detailed co-ordination of material deliveries, designs and articles accurate to day causes builders' significant expenses connected with the content of excessive reserves or extra charges on preparation of material resources per unit of output, as well as promotes occurrence of imaginary deficiencies tending to go subsequently to true deficiencies.

This is a reason that search of deliveries strategy realising detailed (accurate to one day) calculated need for stored resources is important $\mu_{\mathrm{zt}}^{(\tau)}$, which would supply the minimum of total expenditures of the enterprise on construction of bridges on the content of current reserve and deliveries. In the conditions of stationary demand on material produce, when $\mu=$ const, for definition of efficient sizes of the parties $Q^{*}$ and the intervals of deliveries $\mathrm{K}^{*}$ is offered the Wilson-Harris model

$$
Q^{*}=\sqrt{\frac{2 p \mu}{g}}, K^{*}=\sqrt{\frac{2 p}{\mu g}},
$$

where: $\mathrm{p}$ is semi-fixed costs to the organisation of delivery of material produce; $\mathrm{g}$ is expense of storage of the reserve units in unit time.

Research conducted in building divisions of public corporation of "Dalmostostroy", Open Company "MSK-10", Open Company "Building company Most-Vostok", showed 
that at construction of railway bridges consumption of stored resources has, as a rule, a nonuniform character. Coefficient of variation characterising degree of yield rhythm of material and technical production, accounts for 0.5-1.5. Under these conditions additional technology of formation of delivery schedules accounting non-uniformity of demand is necessary. It is represented that in its base should lie dynamic programming method. We will give a mathematical scenario.

Let there be a plenty of resources $M$. It is required to define such sequences of standard items Qz* both the intervals of deliveries $\mathrm{Kz}^{*}$ for $\forall \in \mathrm{M}$, which minimise total expenses W on temporary reserving of resources, caused discrete nature of receipts, and expenditure to the organisation of deliveries of stored resources $z$. $M=\{z / z\}$ - plenty of stored resources.

For definition of the most profitable strategy of deliveries of resources task we segregate into $n$ phases: $1, \ldots, i, \ldots, n-1, n$, where $n$ is value of the plan period. To each phase $i$ corresponds $\mathrm{u}_{\mathrm{zi}}$ of possible deliveries strategies. In total is considered plenty of possible strategies $\mathrm{u}_{\mathrm{zi}}=\mathrm{u}_{\mathrm{z} 1}, \ldots, \mathrm{u}_{\mathrm{zi}}, \ldots, \mathrm{u}_{\mathrm{zn}}$. For each strategy exists determined value of the criterion of optimality $\mathrm{w}_{\mathrm{z}}=\mathrm{w}\left(\mathrm{u}_{\mathrm{z} 1}, \ldots, \mathrm{u}_{\mathrm{zi}}, \ldots, \mathrm{u}_{\mathrm{zn}}\right)=\mathrm{w}\left(\mathrm{u}_{\mathrm{z}}\right)$. The criterion of optimality is the amount of expenses on all phases, i.e. it is an additive function:

$$
\mathrm{w}_{\mathrm{Z}}=\sum_{\mathrm{i}=1}^{\mathrm{n}} \mathrm{w}_{\mathrm{zi}}
$$

where: $\mathrm{w}_{\mathrm{zi}}$ is enterprise expenses, accepted strategy appropriate $\mathrm{u}_{\mathrm{zi}}$ deliveries of resource $\mathrm{z}$ at stage $\mathrm{i}$. It is required to choose such $\mathrm{u}_{\mathrm{zi}}$ для $\forall \in \mathrm{M}$ on the $\mathrm{n}$ phases which would minimise value

$$
\mathrm{W}_{2}=\sum_{\mathrm{z} \in \mathrm{M}} \mathrm{w}_{\mathrm{z}}^{*}=\sum_{\mathrm{z} \in \mathrm{M}} \min \mathrm{u}_{\mathrm{z}} \mathrm{w}\left(\mathrm{u}_{\mathrm{zl}}, \ldots, \mathrm{u}_{\mathrm{zi}}, \ldots, \mathrm{u}_{\mathrm{zn}}\right)=\sum_{\mathrm{z} \in \mathrm{M}} \min \mathrm{u}_{\mathrm{z}}\left\{\mathrm{w}\left(\mathrm{u}_{\mathrm{z}}\right)\right\}
$$

During the first phase can take place the strategies of deliveries of resources $\mathrm{u}_{\mathrm{z}}{ }^{1,1}, \ldots$, $\mathrm{u}_{\mathrm{z} 1}{ }^{\mathrm{k}, \mathrm{j}=\mathrm{k}}, \ldots, \mathrm{u}_{\mathrm{z} 1}^{\mathrm{n}, \mathrm{n}}$ with periodicity of receipt, respectively, $1,2, \ldots, \mathrm{K}, \ldots, \mathrm{n}$ time units (days). For phase $\mathrm{i}$ are possible transitions from conditions $\mathrm{S}_{\mathrm{i}-1}^{\mathrm{j}-\mathrm{k}}$ of phase $\mathrm{i}-1$ to conditions $\mathrm{S}_{\mathrm{i}}^{\mathrm{j}}$. By that transitions are corresponded the strategy $u_{z i}^{(j-k)-j}\left(u_{z i}^{k, j}\right)$, where: $k$ is the values of intervals of deliveries at stage $\mathrm{i}(0 \leq k \leq j-i+1)$; $\mathrm{j}$ is the term of expenditure of current reserve at delivery of resource $\mathrm{z}$, with periodicity $\mathrm{k}$ at stage $\mathrm{i}(i \leq j \leq n)$.

We will show plenty of all elementary strategies of deliveries uzl on the schedule made at length of the horizon of planning $n=6$ days (Figure 3 ), from which it is visible that on each subsequent phase the number of competitive variants decreases, and total of nonrecurrent elementary deliveries strategies is equal the amount of natural series of the numbers, last of which is $n$. 


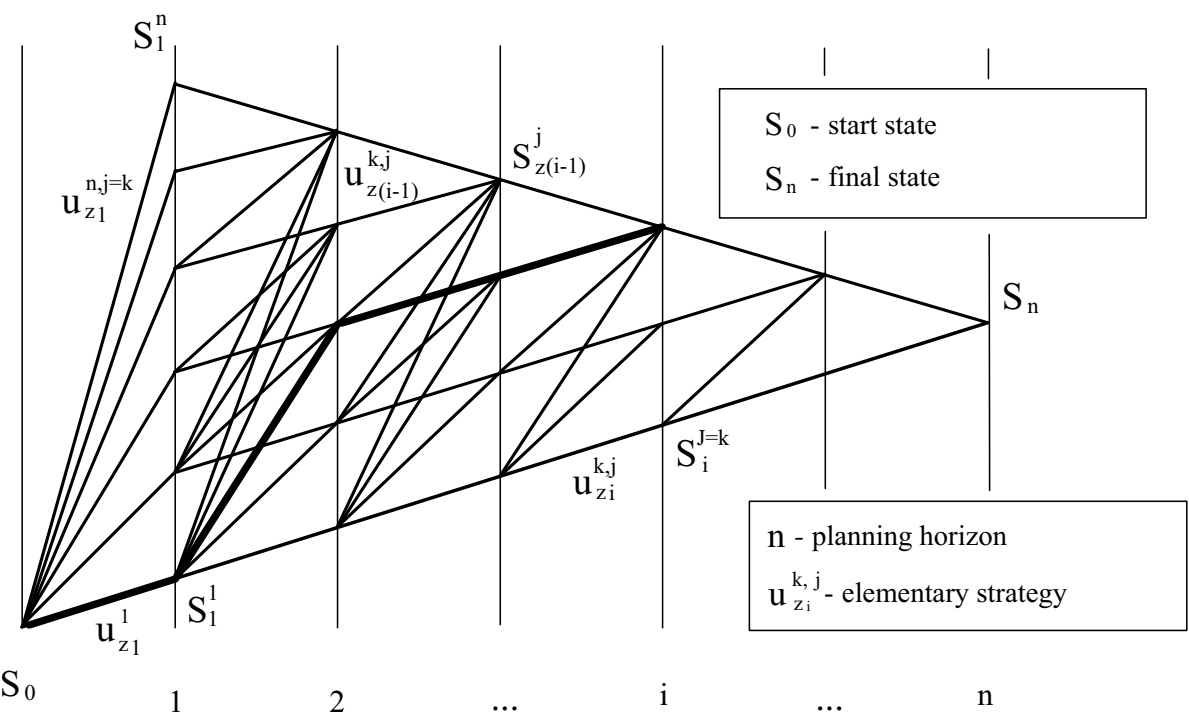

Fig.3. Diagram of deliveries strategies.

We will implement process of search of optimum delivery schedule in following sequence. In the beginning is produced selection of conventional optimum strategies of deliveries $\mathrm{u}_{\mathrm{z}}^{+}=\mathrm{u}_{\mathrm{z} 1}{ }^{+}, \mathrm{u}_{\mathrm{z} 2}{ }^{+}, \ldots, \mathrm{u}_{\mathrm{zi}}{ }^{+}, \ldots, \mathrm{u}_{\mathrm{zn}}{ }^{+}$in the direction from initial condition $\mathrm{S}_{0}$ to ultimate $S_{n}$. Then, in the reverse sequence, beginning with $S_{n}$, we install absolute optimum plan of resources delivery $\mathrm{u}_{\mathrm{z}}{ }^{*}=\mathrm{u}_{\mathrm{z} 1}{ }^{*}, \mathrm{u}_{\mathrm{z} 2}{ }^{*}, \ldots, \mathrm{u}_{\mathrm{zi}}{ }^{*}, \ldots, \mathrm{u}_{\mathrm{zn}}{ }^{*}$.

We will consider process of optimisation in forward direction and separately: on the first and ultimate phases $i$, having some features. The first phase is characteristic what here is no elimination of variants $\mathrm{u}_{\mathrm{zi}}{ }^{\mathrm{k}, \mathrm{j}}$ and initial state $\mathrm{S}_{0}$ entirely known. In view of it, we will record sequence of actions on performance of counting upon first phase of the delivery schedule optimisation:

$$
\mathrm{w}_{\mathrm{z} 0}=0, \mathrm{u}_{\mathrm{zl}}^{\mathrm{k}, \mathrm{j}}=\mathrm{u}_{\mathrm{zl}}^{(\mathrm{k}, \mathrm{j})+} \rightarrow \mathrm{w}_{\mathrm{zl}}^{\mathrm{k}, \mathrm{j}}=\mathrm{w}_{\mathrm{zl}}^{(\mathrm{k}, \mathrm{j})+},\left[\mathrm{u}_{\mathrm{zl}}^{(\mathrm{k}, \mathrm{j})+}, \mathrm{u}_{\mathrm{z}(0-1)}^{\mathrm{j}+}\right]
$$

Value of the criterion of optimality $\mathrm{w}_{\mathrm{zl}}{ }^{\mathrm{k}, \mathrm{j}}$, including expenditures of enterprise on the content of current reserve and expense connected with delivery of material resources $\mathrm{z}$, is defined:

$$
\mathrm{w}_{\mathrm{zl}}^{\mathrm{k}, \mathrm{j}}=\mathrm{g}_{\mathrm{z}} \sum_{\mathrm{l}=0}^{\mathrm{k}} \mu_{\mathrm{z1}}^{\mathrm{j}-1}(\mathrm{k}-1)+\mathrm{h}_{\mathrm{z}} \mathrm{Q}_{\mathrm{zl}}^{\mathrm{k}, \mathrm{j}}+\mathrm{P}_{\mathrm{z}}
$$

where: $h_{z}$ is variable expenditures to the organisation of resource delivery $z$ per unit of output; $\mathrm{Q}_{\mathrm{z} 1}{ }^{\mathrm{k}, \mathrm{j}}$ is size of the delivery party of stored resource $\mathrm{z}$, periodicity $\mathrm{k}$ and the term of it expenditure $\mathrm{j}$. At stage $\mathrm{i}$ choice of conventional elementary strategies $\mathrm{u}_{\mathrm{zi}}{ }^{\mathrm{k}, \mathrm{j}}$ and calculation $\mathrm{w}_{\mathrm{z}(0-\mathrm{i})}^{+}$the appropriate to the strategies $\mathrm{u}_{\mathrm{z}(0-\mathrm{i})}^{+}$is produced in following sequence:

$$
\mathrm{u}_{\mathrm{zi}}^{\mathrm{k}, \mathrm{j}} \rightarrow \mathrm{w}_{\mathrm{zi}}^{\mathrm{k}, \mathrm{j}} \rightarrow \mathrm{w}_{\mathrm{z}(0-\mathrm{i})}^{\mathrm{j}}=\mathrm{w}_{\mathrm{z}[0-(\mathrm{i}-1)]}^{\mathrm{j}+}+\mathrm{w}_{\mathrm{zi}}^{\mathrm{k}, \mathrm{j}} \rightarrow \mathrm{w}_{\mathrm{z}(0-\mathrm{i})}^{\mathrm{j}+}=\min \left[\mathrm{w}_{\mathrm{z}(0-\mathrm{i})}^{\mathrm{j}}\right] \rightarrow \mathrm{u}_{\mathrm{zi}}^{(\mathrm{k}, \mathrm{j})+} \text {. }
$$

Expenditures on the content of current reserve and expense connected with delivery of resources $\mathrm{w}_{\mathrm{zi}}^{\mathrm{k}, \mathrm{j}}$ are defined: 


$$
\mathrm{w}_{\mathrm{zl}}^{\mathrm{k}, \mathrm{j}}=\sum_{\mathrm{l}=0}^{\mathrm{k}} \mu_{\mathrm{zl}}^{\mathrm{j}-1}\left[(\mathrm{k}-1)+\mathrm{h}_{\mathrm{z}}\right]+\mathrm{P}_{\mathrm{z}}
$$

On each subsequent step the amount of considering conditions $\mathrm{S}_{\mathrm{i}}^{\mathrm{j}}$ decreases and on the last phase there is only one condition $\mathrm{S}_{\mathrm{n}}{ }^{\mathrm{j}}{ }^{\mathrm{n}}$. Therefore at stage $\mathrm{n}$, after performance of operations

$$
\mathrm{u}_{\mathrm{zn}} \rightarrow \mathrm{w}_{\mathrm{zn}} \rightarrow \mathrm{w}_{\mathrm{z}(0-\mathrm{n})}=\mathrm{w}_{\mathrm{z}[0-(\mathrm{n}-1)]}^{\mathrm{j}+}+\mathrm{w}_{\mathrm{zn}} \rightarrow \mathrm{w}_{\mathrm{z}(0-\mathrm{n})}^{*}=\min \left[\mathrm{w}_{\mathrm{z}(0-\mathrm{n})}\right]
$$

are installed: conventional optimum elementary strategy $\mathrm{u}_{\mathrm{zn}}{ }^{+}$, which is as well definitely of optimum $\mathrm{u}_{\mathrm{zn}}{ }^{*}$; minimal value of expenditures $\mathrm{W}_{\mathrm{z}(0-\mathrm{n})}{ }^{*}$, , the appropriate to optimum plan of resource receipts $\mathrm{z}$ to enterprise on construction of bridges. Optimum delivery schedule is restored, beginning with final state $S_{n}$ on outline:

$$
\mathrm{S}_{\mathrm{n}} \rightarrow \mathrm{u}_{\mathrm{zn}}^{*}\left(\mathrm{~S}_{\mathrm{n}}\right) \rightarrow \mathrm{S}_{\mathrm{z}(\mathrm{n}-1)}^{*} \rightarrow \ldots \rightarrow \mathrm{u}_{\mathrm{z2}}^{*}\left(\mathrm{~S}_{\mathrm{zz}}^{*}\right) \rightarrow \mathrm{S}_{\mathrm{zl}}^{*} \rightarrow \mathrm{u}_{\mathrm{zl}}\left(\mathrm{S}_{\mathrm{zl}}^{*}\right) \rightarrow \mathrm{S}_{0} .
$$

\section{Reservation of deliveries of resources taking into account reliability of suppliers}

In the closing (the third) stages of plan generation of material security of railway bridges construction updating earlier of accepted decisions is executed. It is caused by deviations of actual terms and sizes of deliveries from calculated. To compensate mismatch of building activity and supplying divisions, it is necessary to provide temporary reserving of earlier determined terms of material resources deliveries. This reserving can be considered as insurance reserves in regards to suppliers. Overestimated values of temporary reserving of stored resources result in increase of expenditures of building enterprises on the content of insurance reserves.

However it promotes increase of reliability timetables on erection of railway bridges. Decrease of temporary reserving of deliveries allows to building organisations cut down expenses connected with mobilisation of resources making insurance reserves in regards to suppliers. But at the same time losses grow owing to deficiency in material production. Hence, inconsistent tendencies affecting sizes of temporary reserving of receipts of stored resources are that sets the task of their optimisation

It is important define such parameters of temporary reserving of delivery schedules, at which steady performance of calendar building schedules and the minimum of total average losses W3 because of storage and deficiency of material resources is supplied.

Mathematical model of task in view looks like:

$$
\mathrm{W}_{3}=\sum_{\mathrm{z} \in \mathrm{Mi}} \sum_{\mathrm{i}=1}^{\mathrm{n}}\left(\mathrm{g}_{\mathrm{zi}} \sum_{\mathrm{x}=0}^{\infty} \mathrm{G}_{\mathrm{z}}(\mathrm{x})+\mathrm{g}_{\mathrm{zi}} \sum_{\mathrm{x}=0}^{\mathrm{t}} \mathrm{G}_{\mathrm{z}}(\mathrm{x})\left(\mathrm{t}_{\mathrm{zi}}-\mathrm{x}\right)+\mathrm{p}_{\mathrm{zi}} \sum_{\mathrm{z}(\mathrm{i}+1)}^{\infty} \mathrm{G}_{\mathrm{z}}(\mathrm{x})\left(\mathrm{x}-\mathrm{t}_{\mathrm{zi}}\right)\right)
$$

where: amount of deliveries in the range plan period; $G_{z}(x)$ s probability of deviations time of resource delivery from scheduled; $\mathrm{g}_{\mathrm{zi}}$ is size of expenditures for reserving of delivery $\mathrm{i}$ of resource $\mathrm{z}$ per unit time; $\mathrm{g}_{\mathrm{zi}}\left(\mathrm{t}_{\mathrm{zi}}-\mathrm{x}\right) \mathrm{G}_{\mathrm{z}}(\mathrm{x})$ is expenses on temporary reserving of delivery $\mathrm{i}$ of resource $\mathrm{z} ; \mathrm{p}_{\mathrm{zi}}$ is size of losses connected with possible deficiency in resource $\mathrm{z} ; \mathrm{p}_{\mathrm{zi}}\left(\mathrm{x}-\mathrm{t}_{\mathrm{zi}}\right) \mathrm{G}_{\mathrm{z}}(\mathrm{x})$ is losses connected with delayed receipt of the party $\mathrm{i}$ of resource $z$ from enterprise-supplier; $g_{z} G_{z}(x)$ is possible expenses of the organisation on construction of bridges at positive deviations of actual terms of deliveries from planned. 
For definition of optimum value $\mathrm{t}_{\mathrm{zi}}$, function of expenditures on temporary reserving of deliveries can be presented as

$$
\mathrm{w}\left(\mathrm{t}_{\mathrm{zi}}\right)=\mathrm{g}_{\mathrm{zi}} \int_{0}^{\infty} \varphi_{\mathrm{z}}(\mathrm{x}) \mathrm{dx}+\mathrm{g}_{\mathrm{zi}} \int_{0}^{\mathrm{t}_{\mathrm{i}}} \varphi_{\mathrm{z}}(\mathrm{x})\left(\mathrm{t}_{\mathrm{zi}}-\mathrm{x}\right) \mathrm{dx}+\mathrm{p}_{\mathrm{zi}} \int_{\mathrm{t}_{\mathrm{zi}}}^{\infty} \varphi_{\mathrm{z}}(\mathrm{x})\left(\mathrm{x}-\mathrm{t}_{\mathrm{zi}}\right) \mathrm{dx},
$$

where variable $\mathrm{x}$ is considered as stochastic and continuously apportioned observation. Optimum level of insurance reserve is defined by the law $\frac{\mathrm{dw}\left(\mathrm{t}_{\mathrm{zi}}\right)}{\mathrm{dt}_{\mathrm{zi}}}=0$. After transformations it acquires kind:

$$
\begin{aligned}
& \frac{\mathrm{dw}\left(\mathrm{t}_{\mathrm{zi}}\right)}{\mathrm{dt}{ }_{\mathrm{zi}}}=\mathrm{g}_{\mathrm{zi}} \frac{\mathrm{d}}{\mathrm{dt}}{ }_{\mathrm{zi}}^{\mathrm{t}} \int_{0}^{\mathrm{zi}}\left(\mathrm{t}_{\mathrm{zi}}-\mathrm{x}\right) \varphi_{\mathrm{z}}(\mathrm{x}) \mathrm{dx}+\mathrm{p}_{\mathrm{zi}} \frac{\mathrm{d}}{\mathrm{dt}}{ }_{\mathrm{zi}} \int_{\mathrm{zi}}^{\infty}\left(\mathrm{x}-\mathrm{t}_{\mathrm{zi}}\right) \varphi_{\mathrm{z}}(\mathrm{x}) \mathrm{dx}= \\
& =\mathrm{g}_{\mathrm{zi}} \int_{0}^{\mathrm{t}} \varphi_{\mathrm{Z}}(\mathrm{x}) \mathrm{dx}-\mathrm{p}_{\mathrm{zi}} \int_{\mathrm{t}}^{\infty} \varphi_{\mathrm{Z}}(\mathrm{x}) \mathrm{dx}=0
\end{aligned}
$$
follows:

In practical calculations the condition of optimum guarantee reserve appears as

$$
\mathrm{F}_{\mathrm{z}}(\mathrm{x})=\int_{0}^{\mathrm{t}_{\mathrm{i}}} \varphi_{\mathrm{z}}(\mathrm{x}) \mathrm{dx}=\mathrm{b}_{\mathrm{z}} \frac{\mathrm{p}_{\mathrm{zi}}}{\mathrm{g}_{\mathrm{zi}}+\mathrm{p}_{\mathrm{zi}}}
$$

where: $\mathrm{b}_{\mathrm{z}}=\int_{0}^{\infty} \varphi_{\mathrm{z}}(\mathrm{x}) \mathrm{dx}$ is probability, the appropriate to negative deviations of material resources deliveries. In such a manner, knowing function of distribution $\mathrm{F}_{\mathrm{z}}(\mathrm{x})$, expenditure of $\mathrm{p}_{\mathrm{zi}}$ and $\mathrm{g}_{\mathrm{zi}}$, and using the condition of the optimality, can be defined optimum sizes of temporary reserving of resources in regards to suppliers. Calculated values $t_{\mathrm{zi}}$ allow to specify the terms of resources deliveries received at the second stage of plan generation of material security of construction. When difficult to define size of losses at the engineering of railway bridges, owing to deficiency in stored resources $\mathrm{p}_{\mathrm{zi}}$ sizing of time reservation $\mathrm{t}_{\mathrm{zi}}$ can be based not to the criteria of the mean of distribution minimum of enterprise expenditures on construction of bridges, but on probability of deficiency absence at deliveries delay. Shortage probability or risk ratio $\alpha_{\mathrm{z}}=\int_{\mathrm{t}_{\mathrm{i}}}^{\infty} \varphi_{\mathrm{z}}(\mathrm{x}) \mathrm{dx}$, depending on importance of supplied resources, can be installed at a rate of 0,003-0,1. Knowing the type of distribution $\mathrm{Q}_{\mathrm{z}}(\mathrm{x})$ and establishing risk ratio $\alpha_{\mathrm{z}}$, can be defined rational values of temporary reserving in regards to suppliers from formula

$$
\mathrm{F}_{\mathrm{z}}(\mathrm{x})=\int_{\mathrm{t}_{\mathrm{z}}}^{\infty} \varphi_{\mathrm{z}}(\mathrm{x}) \mathrm{dx}=\alpha_{\mathrm{z}} .
$$

The reconciliation procedures of graphical schedule of railway bridges on the section of railroad line with timetables of resources deliveries can be consideredfinalised, if generated plans of material supplying correspond production programs of supplying divisions. At impossibility matching of plans supplies resources with output schedules by manufacturers is produced either updating of production program of the structure of railway bridge crossings or change of the planned production of supplying divisions. 


\section{Conclusions}

1. On present stage of railway construction realised in difficult conditions of Northern and Far East regions of Russia, volumes and complexity of works on erection of railway bridge crossings substantially grow. Under these conditions is necessary detailed synchronisation of building programme of bridges and supplying programs. Important place in their realisationis taken away to improvement of planning demand for material resources, to development of delivery schedules, to definition of insurance reserves considering specification and nature of delivery.

2. Accomplished statistical analysis of realisation diagram schedule of bridges construction from the standpoint of observance of terms performances of works allowed to define quantitative evaluations of developed timetables stability. It provided decision, on essentially new base, of optimization problems of temporary reserving of demand to materials, designs and articles.

3. Optimisation technology of supply planning is prepared to platforms on erection of railway bridges considering non-stationary consumption of material production. Received recommendations on the basis of dynamic programming method allow to define volumes and deliveries intervals supplying the minimum of expenditures on the content of current reserve and logistic.

4. Necessity of plans revision supply of materials for railway bridges construction is shown in view of probability nature of the enterprises-suppliers activity. For compensation of activity mismatch of building and supplying divisions it is offered to provide insurance reserves in regards to suppliers. Mathematical model and the definition technique of rational definition parameters of temporary reserving of delivery schedules is discussed, at which is supplied steady performance of calendar building schedules and the minimum of total average losses because of storage and the deficiency of material resources is reached.

\section{References}

1. G.Cedillo, J.De la Riva, A.Bueno, J. Gonzalez, J.García, DYNA 81(187), 232239(2014)

2. S.Adamczyk,A.C. Bullinger, K.M.Möslein, Creativity and Innovation Management 21(4), 335-360 (2012)

3. A.Armisen, A.Majchrzak, Business Horizons58(4), 389-399 (2015)

4. B.L.Bayus, Management Science59(1), 226-244 (2013)

5. M.S.Klykov, A.V.Zemskov, E.I. Loseva, The Far East: problems of development of architectural-building and road-transport complex15, 22-28 (2015)

6. P.Burnson, Logistics Management 52(6), 56-70 (2013)

7. K.Kalogerakis,N.Wagenstetter, Epubli GmbH1, 27-47 (2014)

8. M.S.Klykov, A.N.Suldin, N.P. Grigoryev, Prospects of development of transport infrastructure of the Far East 4, 230-234 (2016)

9. J.Gonzalez, G.Cedillo, J.Garcia, DYNA 81(187), 249-256 (2014)

10. O.Gassmann, S.Friesike, M.Daiber, Springer International Publishing 1, 75-87 (2014)

11. Z. Popović, L. Lazarevic, N.Vatin, Procedia Engineering, 117 (1), 846-853 (2015) DOI: $10.1016 /$ j.proeng.2015.08.149

12. S. Ognjenovic, R. Donceva, N. Vatin. Procedia Engineering, 117 (1), 549-555 (2015) DOI: $10.1016 /$ j.proeng.2015.08.210 
13. S. Ognjenovic, Z. Krakutovski, N. Vatin. Procedia Engineering, 117 (1), 564-572 (2015) DOI: 10.1016/j.proeng.2015.08.214

14. S. Ognjenovic, R. Donceva, N. Vatin. Procedia Engineering, 117 (1), 556-563 (2015) DOI: 10.1016/j.proeng.2015.08.212

15. S. Ognjenovic, R. Ristov, N. Vatin. Procedia Engineering, 117 (1), 573-578 (2015) DOI: $10.1016 /$ j.proeng.2015.08.215

16. S. Ognjenović, Z. Zafirovski, N. Vatin. Procedia Engineering, 117 (1), 579-584 (2015) DOI: 10.1016/j.proeng.2015.08.216 